\title{
Herpes zoster (Shingles)
}

\section{MH Motswaledi}

Department of Dermatology, Sefako Makgatho Health Sciences University

*Corresponding author, email: motswaledi1@webmail.co.za

\begin{abstract}
Herpes zoster or Shingles is caused by varicella-zoster virus (VZV), the same virus that causes chicken-pox (varicella).

Primary infection with varicella-zoster virus causes chicken-pox (varicella), then the virus persists in nerve ganglia of sensory but rarely motor nerves, in a latent stage.

If the virus gets reactivated it causes herpes zoster, which presents as painful vesicles following a dermatome. It is more common in the elderly and the immunocompromised.

Herpes zoster is a common skin and mucous membrane disease caused by reactivation of latent varicella zoster virus, which had lodged previously in nerve ganglia.

Trigeminal nerve nuclei and thoracic spinal ganglia are the most commonly affected.

Reactivation of latent varicella-zoster virus can be triggered by old age, that is why herpes zoster is common in the elderly, above 60 years of age. This is due to age related decline in specific cell mediated immune response to VZV. Other triggering factors are malignancies malnutrition, emotional stress, physical trauma, chronic diseases like diabetes mellitus and immunosuppression from drugs and HIV., ${ }^{1,2}$
\end{abstract}

Keywords: Herpes zoster, Shingles

\section{Clinical presentation}

Herpes zoster typically presents with pain followed by erythema and eruption of vesicles on the affected dermatome. The pain of herpes zoster is variously described as sharp, stabbing, shooting, burning, throbbing or tender., ${ }^{1,3}$

VZV can reactivate and cause pain without eruption of vesicles. This is referred to as zoster sine herpete $(\mathrm{ZSH})$ or zoster sine eruptione. ${ }^{4,5}$

If the trigeminal nerve is involved, differentiating ZSH from idiopathic trigeminal neuralgia can be difficult, but clinical history can be helpful as the pain of ZSH is more continuous like postherpetic neuralgia rather than the intermittent pain of idiopathic trigeminal neuralgia. ${ }^{6}$

Patients with herpes zoster may be infectious from the skin lesions and in susceptible contacts of herpes zoster, chicken pox can occur, especially in children.,

The time between the start of pain and the onset of the eruption is about one and a half days in trigeminal zoster and about three days in thoracic disease. ${ }^{4}$

The vesicles always follow a dermatome or two contiguous dermatomes (Figure 1, Figure 2). Mucous membranes in the affected dermatomes are also affected. Regional lymphadenopathy is common.

Uncomplicated cases are self-limiting and recovery occurs in 2-4 weeks. Herpes zoster usually occurs only once in an individual's lifetime, but recurrences are frequent in the immunocompromised.

\section{Herpes zoster ophthalmicus}

This is herpes zoster involving the ophthalmic division of trigeminal nerve, the fifth cranial nerve ( Figure 3). Secondary bacterial infection with a purulent discharge from the affected eye is common (Figure 4).

The ophthalmic division further branches into nasociliary, frontal and lacrimal nerves. Involvement of these branches results in involvement of anterior and posterior ethmoidal sinuses, skin of upper and lower eyelids, the tip of the nose, conjuctiva, sclera, cornea, iris and choroid.

Ocular involvement occurs in $50 \%$ of patients with herpes zoster ophthalmicus. Anterior segment complications include episcleritis, scleritis, sclerokeratitis, uveitis and corneal perforation. ${ }^{7}$ Posterior segment complications include retinal perivasculitis, ischaemic optic neuritis, and necrotising retinopathy resulting in permanent loss of vision (Figure 5). 


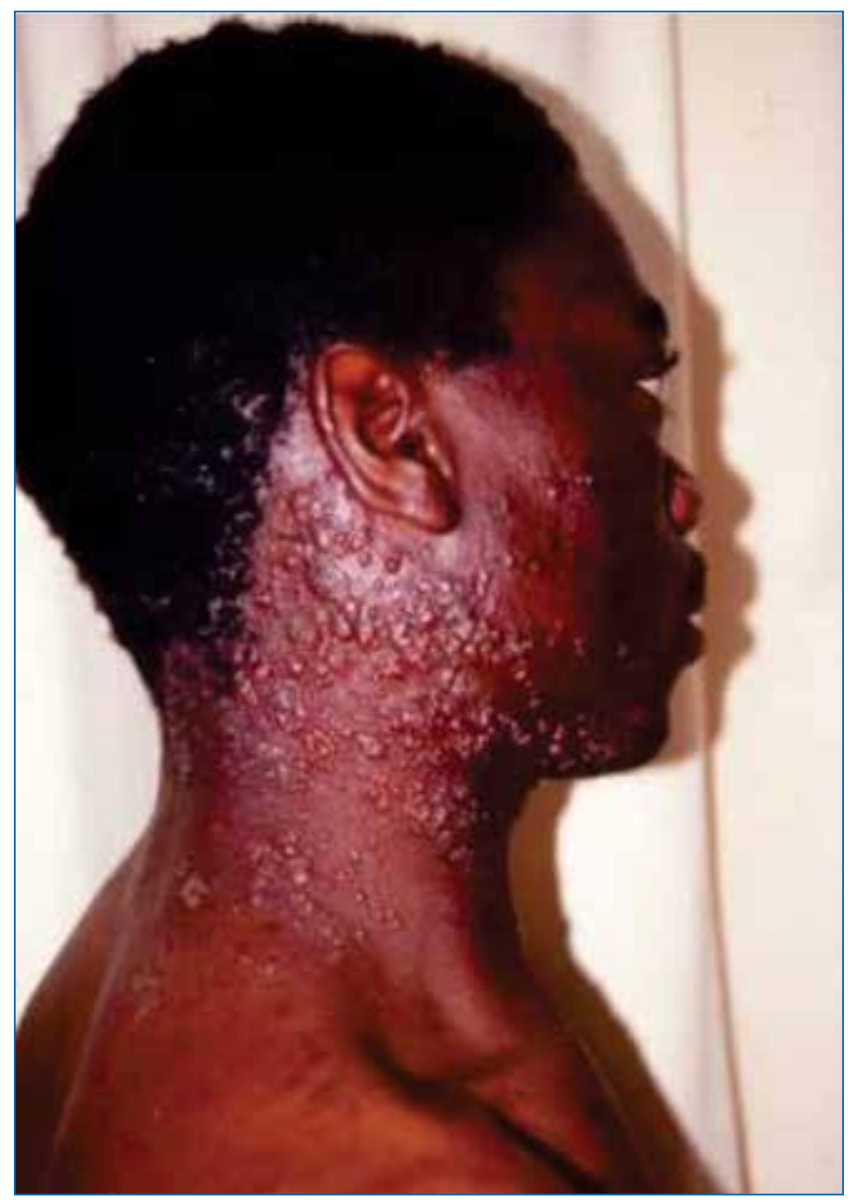

Figure 1: Herpes zoster affecting the neck.

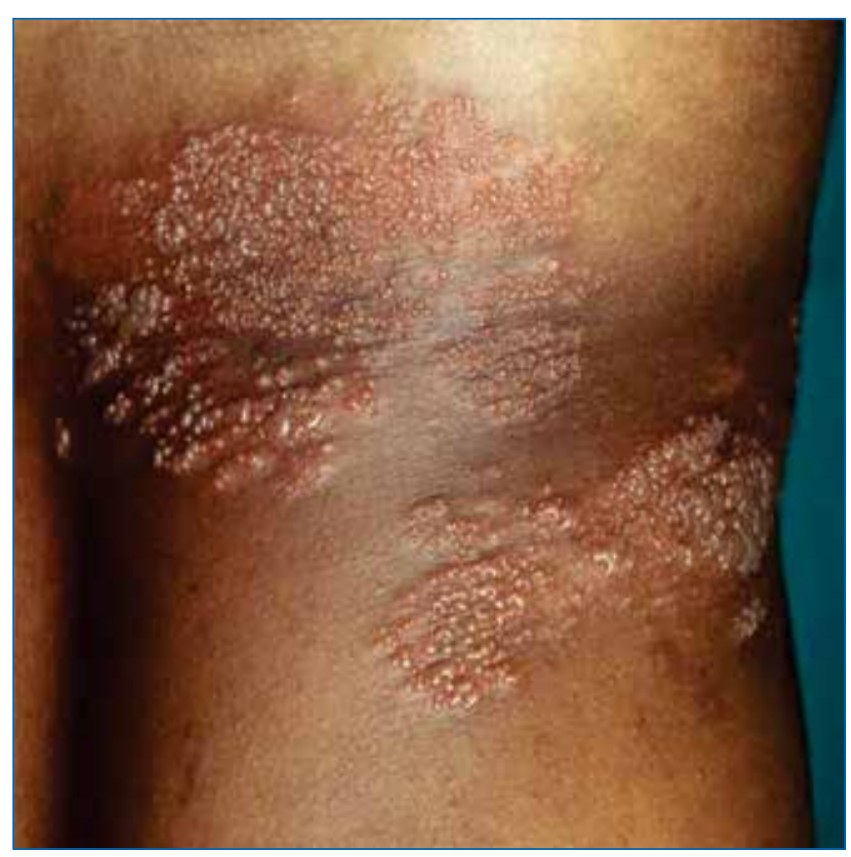

Figure 2: Herpes zoster affecting the trunk.

\section{Herpes zoster oticus}

Although the facial nerve is mainly a motor nerve, it has vestigial sensory fibres supplying the external ear.

Sensory nerve zoster in these fibres causes pain and vesicles in the distribution of these fibres. Swelling of the infected sensory fibres in their course through the facial canal and internal

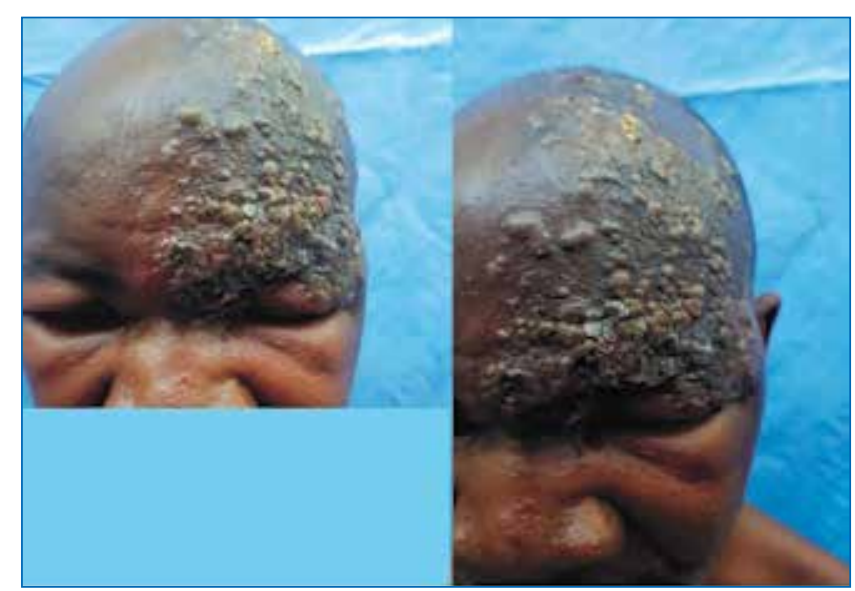

Figure $3(a)$ and $3(b)$ : Herpes zoster affecting the ophthalmic division of trigeminal nerve.

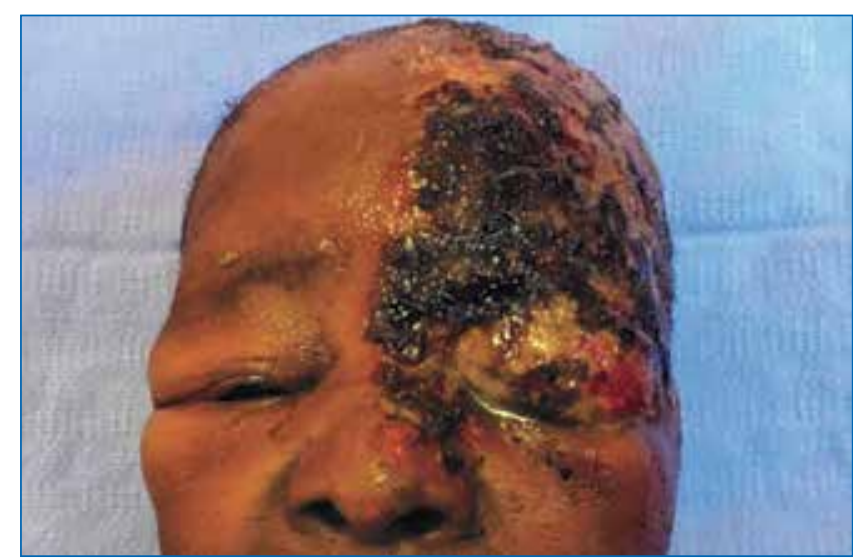

Figure 4: Secondary bacterial infection with a purulent discharge from the eye.

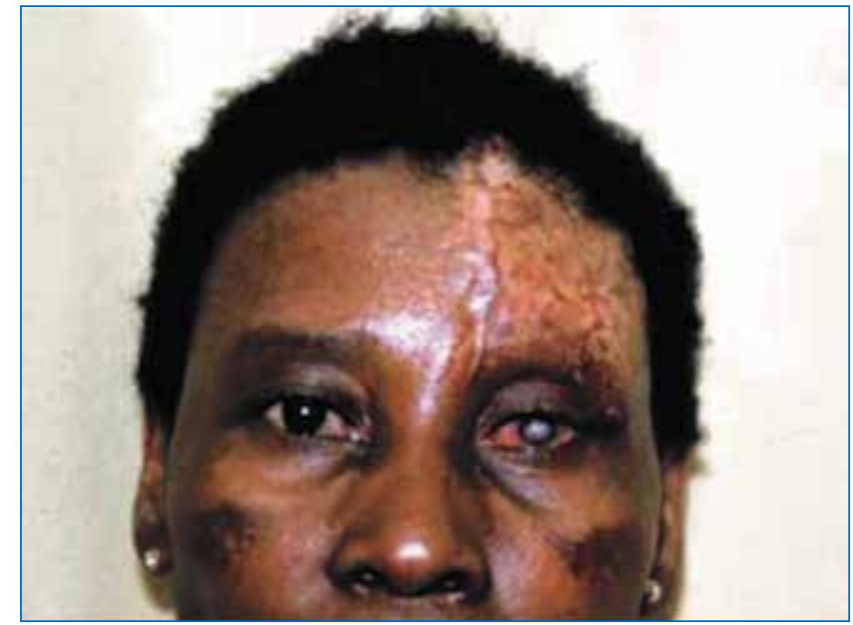

Figure 5: Permanent loss of vision due to ophthalmic zoster.

auditory meatus may lead to compression of adjacent neural structures, resulting in facial nerve palsy. Facial nerve palsy, ear pain and associated vesicles in the ear form a triad of RamseyHunt syndrome. ${ }^{8}$

Compression of the vestibulo-cochlear nerve may cause sensorineural hearing loss, dizziness and vertigo.

\section{Herpes zoster in HIV}

Herpes zoster is common in HIV and in some cases it may be the first sign of immunosuppression. In the setting of HIV, 
herpes zoster may be multidermatomal or cause a disseminated cutaneous infection. About $20-30 \%$ of patients with HIV develop one or more subsequent episodes of herpes zoster which may involve the same or different dermatomes. ${ }^{9}$ Herpes zoster in HIV may have atypical cutaneous presentation with multiple hyperkeratotic papules which do not follow dermatomal pattern. There may also be ecthymatous lesions with punched out ulceration with central eschar and peripheral rim of vesicles. ${ }^{9}$

\section{Treatment of herpes zoster}

The main aim of treatment in herpes zoster is to reduce or eliminate the pain. Treatment involves antiviral therapy, antiinflammatory drugs and analgesics. ${ }^{3}$

Valacyclovir $1 \mathrm{~g}$ p.o. three times daily for 7 days, given within 72 hours of the onset of the vesicles, reduces acute pain and the duration of chronic pain in patients with herpes zoster. ${ }^{1}$ Analgesic therapy in the form of opiate or non-opiate analgesic drugs should be given to control the pain. The choice of analgesic will depend on pain severity, underlying conditions and drug tolerability. The use of corticosteroids in herpes zoster is controversial. ${ }^{10}$ In some clinical trials corticosteroids were found to reduce the pain of herpes zoster. Some experts recommend the use of oral corticosteroids in patients with moderate to severe pain, if there are no contraindications to the use of corticosteroids. ${ }^{3,10}$ In patients with herpes zoster ophthalmicus, oral antiviral therapy should be offered, even if it is more than 72 hours and up to 7 days following the onset of the rash. This can help to reduce ocular complications. ${ }^{8}$

\section{Complications}

They include impaired vision and stroke secondary to granulomatous arteritis of the internal carotid artery in ophthalmic herpes zoster. This may later result in delayed contralateral hemiparesis, weeks or months after the episode of ophthalmic herpes zoster. It usually presents as headache and hemiplegia, secondary to stroke on the side contralateral to the original rash. ${ }^{8}$

Chronic encephalitis occurs almost exclusively in immunocompromised patients. ${ }^{8,9}$ It also occurs months after the episode of ophthalmic herpes zoster. These are multifocal lesions in the white matter with small vessel vasculitis and demyelination. Clinically it presents with headache, fever, changes in mental status, seizures and other neurologic defects like aphasia and hemiplegia. ${ }^{8,9}$

Postherpetic neuralgia (PHN) is a dermatomal pain persisting at least 90 days after the appearance of the acute herpes zoster rash. ${ }^{1,1}$ It is the most frequent complication of herpes zoster and the most common neuropathic pain resulting from an infection." It is the most debilitating aspect of herpes zoster.

The pain may be constant (described as burning or throbbing), intermittent (described as stabbing or shooting) and stimulusevoked (described as tender). ${ }^{1,3}$
Patients may experience pain from the affected area, from light touch by trivial things like cold wind, or contact with clothing. These various types of chronic pain may result in sleep disturbances, chronic fatigue, depression, anorexia and weight loss. Treatment of PHN is difficult. Recent clinical trials indicate that topical lidocaine, gabapentin, pregabalin, opioids, tricyclic antidepressants and anticonvulsants can significantly reduce the pain of PHN. ${ }^{1,3,10}$

The pain may persist for years or for life, therefore medication is often required over prolonged periods." Risk factors for postherpetic neuralgia include older age, greater severity of the rash, severe pain during the acute phase and immunosuppression. $1,8,11$

Other complications of herpes zoster include myopathies, peripheral and cranial nerve palsies including Bell's palsy, vertigo and hearing loss in herpes zoster oticus. The risk of complications of herpes zoster is high in the elderly and the immunocompromised. ${ }^{8}$

A new herpes zoster vaccine called Shingrix was approved by the FDA in 2017 and it shows promising results. Shingrix reduces the risk of herpes zoster significantly. It boosts VZV specific cellmediated immunity. It contains a component of the varicella zoster virus, and it primes the immune system to recognise the virus if it reactivates. Shingrix differs from the previous vaccine because it contains an adjuvant called ASO1 which increases the body's immune response. ${ }^{2}$ It is given in two doses at least eight weeks apart. Its side effects include pain on the injection site, fatigue, myalgia and headache., ${ }^{2,12}$

\section{References}

1. Johnson RW, Wasner G, Saddier P, et al. Herpes Zoster and Postherpetic Neuralgia Optimizing Management in the Elderly Patient. Drugs Aging. 2008:25(12);991-1006.

2. Bharucha T, Ming D, Breuer J. A critical appraisal of "Shingrix', a novel herpes zoster subunit vaccine (HZ/Su or GSK 1437173A) for varicella zoster virus. Hum Vaccin Immunother. 2017;13(8);1789-97.

3. Schmader K. Herpes Zoster in Older Adults. Aging and Infect Dis. 2001:32;1481-6.

4. Sterling JC, Kurtz JB. Viral infections. In: Champion RH, Burton JL, Burns DA, Breathnach SM, eds. Rook's textbook of Dermatology, 6th ed. Oxford. Blackwell Science, 1998;26:995-1095.

5. Arnold N, Messaoudi I. Herpes Zoster and the search for an effective vaccine. Clin Exp Immunol. 2016;187;82-92.

6. Spector AR. Treatment of Trigeminal Neuralgia with Anti-viral Therapy for Zoster: A case report. Cureus. 10(2):e2144. doi: 10.7759/cureus.2144

7. Liesegang TJ. Herpes Zoster Ophthalmicus. Natural History, Risk factors, Clinical Presentation, and Morbidity. Ophthalmology. 2008;115(2):S3-S12.

8. Volpi A. Severe Complications of Herpes Zoster. Herpes. 2007;14:35A-39A.

9. Gnann JW Jr. Varicella-Zoster Virus: Atypical Presentations and Unusual Complications. J Infect Dis. 2002;186(1):S91-S98.

10. Choudhary S, Dhande S, Kharat $S$, et al. Safety and efficacy of different systemic treatment modalities for acute pain of herpes zoster: A pilot study. Indian Dermatol Online J. 2018;9:101-4.

11. Johnson RW, Rice AS. Postherpetic Neuralgia. N Engl J Med. 2014;371:1526-33.

12. Vink $P$, Shiramoto $M$, Ogawa $M$, et al. Safety and immunogenicity of Herpes Zoster subunit vaccine in Japanese population aged $\geq 50$ years when administered subcutaneously vs. intramuscularly. Hum Vaccin Immunother. 2017;13(3): 574-8 